\title{
A Model Defining the Relationship Between Temperature and Leaf Wetness Duration, and Infection of Watermelon by Colletotrichum orbiculare
}

\author{
J. S. Monroe, Former Graduate Research Assistant, Department of Botany and Plant Pathology, J. B. Santini, Re- \\ search Statistical Analyst, Department of Agronomy, and R. Latin, Professor, Department of Botany and Plant \\ Pathology, Purdue University, West Lafayette, IN 47907
}

\begin{abstract}
Monroe, J. S., Santini, J. B., and Latin, R. 1997. A model defining the relationship between temperature and leaf wetness duration, and infection of watermelon by Colletotrichum orbiculare. Plant Dis. 81:739-742.

Controlled environment experiments were conducted to determine the relationship between temperature, leaf wetness duration, and infection of watermelon by Colletotrichum orbiculare. Flats of watermelon seedlings were inoculated and exposed to various combinations of temperature $\left(12,15,18,21,24,27\right.$, and $\left.30^{\circ} \mathrm{C}\right)$ and leaf wetness duration $(2,4,8,12,16$, and $24 \mathrm{~h})$. The experimental design was a split-plot, with whole units represented by temperature and subunits represented by leaf wetness duration. Anthracnose incidence, defined as the percentage of symptomatic seedlings in each flat 10 days after inoculation, increased with increasing leaf wetness duration at all levels of temperature. The optimum temperature for infection ranged from 21 to $24^{\circ} \mathrm{C}$. At most temperatures, as little as $2 \mathrm{~h}$ of leaf wetness was required for infection. Analysis of variance with orthogonal polynomial contrasts and multiple regression procedures was used to define the relationship of anthracnose incidence to temperature and leaf wetness duration.
\end{abstract}

Additional keywords: cucurbit anthracnose

Anthracnose, caused by Colletotrichum orbiculare (Berk \& Mont.) Arx (=C. lagenarium (Pass.) Ellis \& Halst.), is an important disease of watermelon (Citrullus lanatus (Thunb.) Matsum \& Nakai) in the midwestern and eastern United States. The disease produces symptoms on leaves, stems, and fruit. Defoliation caused by stem and foliar infections can result in substantial reductions in bulk yield $(1,15)$. Also, because symptomatic fruit are unmarketable, outbreaks of anthracnose can result in total losses in some fields (9).

Control options for management of anthracnose are limited. Host resistance to $C$. orbiculare is not available in preferred watermelon cultivars, but farmers can reduce the threat of serious anthracnose outbreaks through standard cultural practices, such as rotation with nonhost crops. However, because of the very low tolerance for fruit infection, growers must rely upon repeated applications of protective fungicides for acceptable levels of disease control. After years of marginal control with

Corresponding author: Richard Latin
E-mail: latin@btny.purdue.edu

Purdue University Agricultural Experiment Station Journal Series No. 15141.

Accepted for publication 20 March 1997.

Publication no. D-1997-0424-07R

(C) 1997 The American Phytopathological Society other fungicides, commercial farmers in Indiana use chlorothalonil and mancozeb applied at 7- or 10-day intervals throughout the growing season.

There are several published reports concerning the effect of environmental conditions on anthracnose development on cucurbits and other hosts. Gardner and Gilbert (7) observed that anthracnose of watermelon was not a problem at temperatures greater than $30^{\circ} \mathrm{C}$. A period of leaf wetness following conidial deposition was necessary for infection of cucumber by the anthracnose pathogen (11). Also, a direct relationship was established between length of dew period and anthracnose development on seedlings of Xanthium spinosum (13). Temperatures between 20 and $25^{\circ} \mathrm{C}$ during the dew period resulted in highest disease ratings, but extended dew periods of $48 \mathrm{~h}$ are necessary for disease development at temperatures below $16^{\circ} \mathrm{C}$.

Empirically determined relationships between environmental factors and anthracnose have been used to help time fungicide sprays. It has been suggested that rainfall accumulations can be used to schedule fungicide sprays for cucumber anthracnose control (17). More recently, Duthie et al. (4) reported a decision rule based on temperature and precipitation for scheduling fungicide sprays for controlling watermelon anthracnose. A weather-based system was recently developed for scheduling fungicide sprays for control of Alter- naria leaf blight of muskmelon $(5,10)$. Since most muskmelon growers in the midwestern United States also raise watermelons, development of a forecaster for watermelon disease would be a logical next step toward implementation of modern disease management practices. Objectives of this research were to define the relationship between temperature and leaf wetness duration and infection of watermelon by $C$. orbiculare, and to develop a model for indexing environmental conditions in terms of favorability for anthracnose development.

\section{MATERIALS AND METHODS \\ Plant production. Watermelon seeds} (cv. Crimson Sweet, Asgrow Seeds, Kalamazoo, MI) were sown into 16-cell flats at one seed per cell. Flats were created by cutting commercially manufactured plastic growing trays with 128 cells (TLC Polyform, Inc., Plymouth, MN) into 16-cell squares. Each cell volume was approximately $25 \mathrm{ml}$ and was filled with a soilless potting medium (Sunshine Mix LC1, Fison's Horticulture, Bellevue, WA). Plants were irrigated from above prior to inoculation and subirrigated after inoculation. Seedlings were inoculated when cotyledons were fully expanded and the first true leaf was emerging. Time from planting to inoculation ranged from 7 to 14 days. Greenhouse temperature and relative humidity ranged from 18 to $33^{\circ} \mathrm{C}$ and 37 to $85 \%$, respectively, and were recorded with a WeatherLog Relative Humidity and Temperature Log (RainWise, Inc., Bar Harbor, ME).

Inoculum production and inoculation technique. Inoculum was increased from an isolate of $C$. orbiculare (no. 9319, R. Latin, Purdue University) collected from infected watermelon in southwestern Indiana. Cultures were maintained on acidified potato dextrose agar (APDA) in 9-cm petri dishes under a 12-h photoperiod at $24 \pm$ $2{ }^{\circ} \mathrm{C}$. Sections of the sporulating cultures were added to vials containing $5 \mathrm{ml}$ of a sterile 1-g/liter suspension of streptomycin sulfate (Agristrep, 21.2 WP, Merck, Inc., Rahway, NJ). Approximately $1 \mathrm{ml}$ of the suspension was pipetted onto the surface of new 9-cm petri dishes with APDA and incubated under the conditions just described for 14 days.

Conidia were washed from the cultures with deionized water and filtered through a 
double layer of surgical gauze. The conidial suspension was adjusted to a concentration of $50,000 \pm 5,000$ conidia per $\mathrm{ml}$ with the aid of a hemacytometer. It had been determined from previous experiments that 50,000 conidia per $\mathrm{ml}$ was an effective concentration to use for inoculation (14). Seedlings in flats were inoculated by misting plants with the inoculum suspension using a hand-held plastic spray bottle. Each flat received an average of 3.2 $\mathrm{ml}$ of conidial suspension. Seedlings were not misted to runoff.

Experimental technique and design. Experiments were conducted at seven temperatures $\left(12,15,18,21,24,27\right.$, and $\left.30^{\circ} \mathrm{C}\right)$ and six leaf wetness durations $(2,4,8,12$, 16 , and $24 \mathrm{~h})$. The saturated environment for the leaf wetness periods was created in a dew chamber (Percival Model I-35 D, Boone, IA). At each temperature, 18 inoculated flats were placed in the dew chamber. Three replicate flats were removed at each prescribed leaf wetness duration and transferred to a growth chamber (Environmental Growth Chambers Model M-31, Chagrin Falls, $\mathrm{OH}$ ) where the same temperature was maintained as in the dew chamber. Relative humidity in the growth chamber ranged from 18 to $35 \%$. After $24 \mathrm{~h}$, all flats were returned to the greenhouse bench. Temperature and relative humidity in the chambers and the greenhouse were monitored and recorded with an electronic temperature and relative humidity logger (RainWise, Inc., Bar Har-
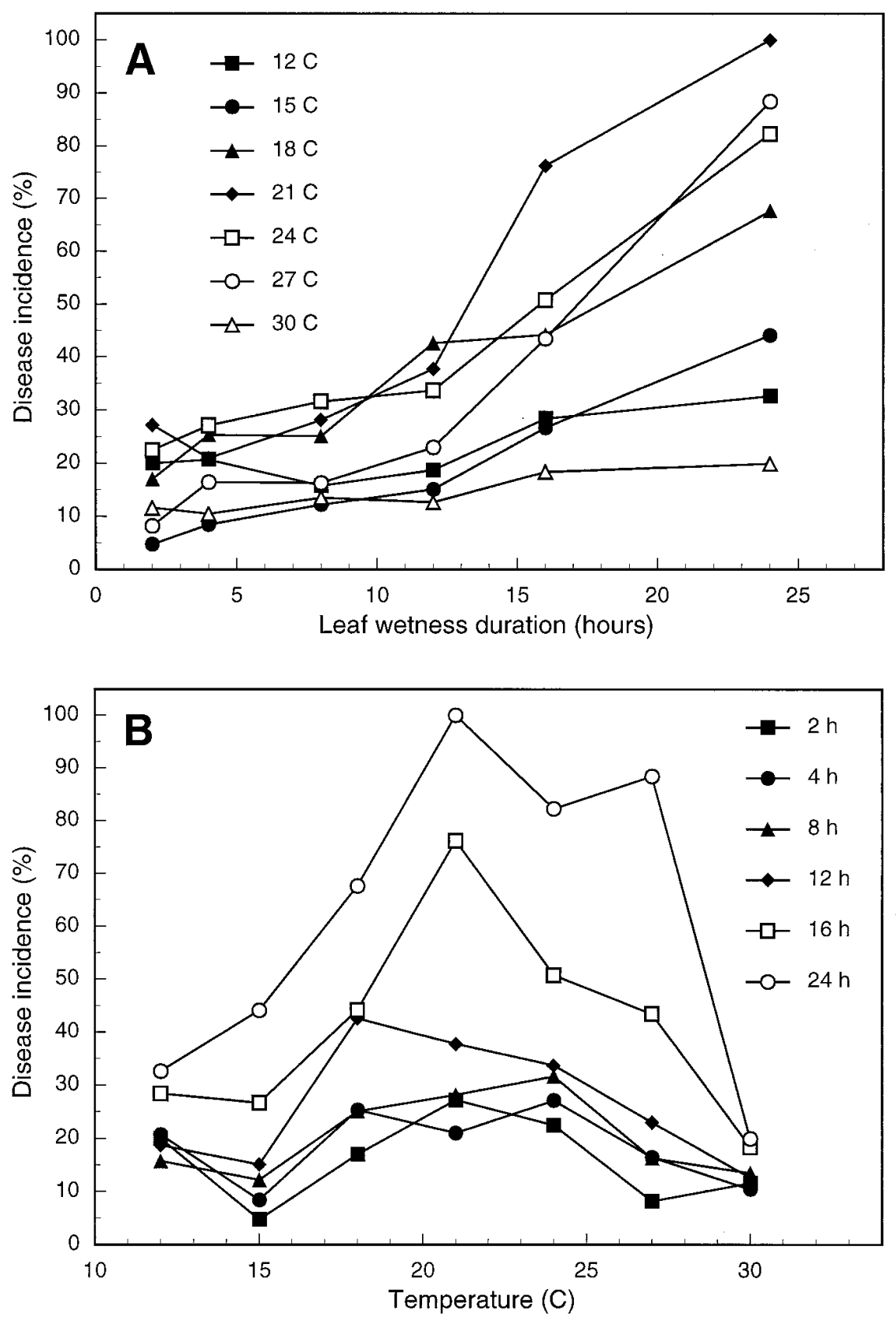

Fig. 1. Observed mean anthracnose incidence at various (A) leaf wetness durations and (B) temperatures.

bor, ME). Temperatures to be tested were selected in random order.

Each temperature-leaf wetness duration combination was repeated twice. The experimental design was a split-plot with whole units arranged in a randomized complete block (16). Whole units were represented by temperature, and the three replications of temperature in time served as blocks. Subunits were represented by leaf wetness duration. Three replicate flats of each wetness duration within every whole unit gave a pure subunit error.

Disease was assessed as the percentage of seedlings per flat that exhibited characteristic anthracnose lesions on stems or leaves 10 days after inoculation.

Data analysis and model development. Disease percentages $(Y)$ were transformed to angles by use of the arcsine transformation $\left(\sin ^{-1} Y^{1 / 2}\right)$ prior to analysis of variance. Analysis of variance and multiple regression procedures were used to define the relationship between environmental factors and infection by $C$. orbiculare. The analysis of variance model (16) was the following (eq. 1): $\sin ^{-1}\left(Y_{i j k l}\right)=\mu+R_{i}+T_{j}+a_{(i j)}+$ $W_{k}+T W_{i k}+b_{(i j k)}+b^{\prime}{ }_{(i j k) l}$, where $Y_{i j k l}$ is the anthracnose percentage of the ijklth individual flat; $\mu$ is the overall population mean; $R_{i}$ is the effect of the $i$ th replication in time; $T_{j}$ is the effect of the $j$ th temperature; $a_{(i j)}$ is the random effect of the $i j$ th whole unit; $W_{k}$ is the effect of the $k$ th leaf wetness duration; $T W_{j k}$ is the interaction of the $j$ th temperature and the $k$ th leaf wetness duration; $b_{(i j k)}$ is the random effect of the $i j$ th block by wetness and $i j k$ th block by temperature by wetness interactions; and $b^{\prime}{ }_{(i j k) l}$ is the random effect of the $l$ th subunit replicate within the $i j k$ th combination.

Statistical procedures were performed with SAS (SAS Institute, Cary, NC) for all data analyses. Sums of squares for temperature, leaf wetness duration, and the temperature by leaf wetness duration interaction were partitioned using orthogonal polynomial coefficients computed by the SAS (IML) ORPOL function. A polynomial model was constructed using significant sources of variation from the analysis of variance results and all lower order terms.

Data from the second run (replication) of the $21^{\circ} \mathrm{C}$ temperature leaf wetness duration experiment were discarded as outliers after a dew chamber malfunction resulted in variable ambient moisture and temperature during the 24-h period. Missing values were generated in part by the SAS GLM procedure using analysis of covariance (16). The degrees of freedom were adjusted accordingly.

\section{RESULTS}

In general, disease incidence increased with leaf wetness duration at all levels of temperature. Incidence ranged from 0 to $100 \%$, with the maximum disease occurring at 24-h leaf wetness duration. For all 
but the highest and lowest temperatures tested, significant increases in disease resulted between 12- to 16-h wetness and 16to 24-h wetness (Fig. 1A). Disease incidence was greatest at $21^{\circ} \mathrm{C}$. High $\left(30^{\circ} \mathrm{C}\right)$ and low $\left(12\right.$ and $\left.15^{\circ} \mathrm{C}\right)$ temperatures resulted in the least amounts of infection (Fig. 1B).

The analysis of variance indicated a significant quadratic relationship between $\sin ^{-1} Y^{1 / 2}$ and temperature, and highly significant linear and significant quadratic relationships between $\sin ^{-1} Y^{1 / 2}$ and leaf wetness duration (Table 1). The analysis of variance also identified two significant temperature by leaf wetness duration interactions. Blocks were nonsignificant and pooled with the whole unit error.

Infection model. The relationship between temperature, leaf wetness duration, and infection of watermelon by $\mathrm{C}$. orbiculare was best defined by the following model (eq. 2): $\sin ^{-1} Y^{1 / 2}=b_{0}+b_{1} T+b_{2} T^{2}$ $+b_{3} T^{3}+b_{4} W+b_{5} W^{2}+b_{6} T W+b_{7} T^{2} W+$

Table 1. Analysis of variance of the arcsine transformation in degrees of watermelon anthracnose incidence for various combinations of temperature and leaf wetness duration

\begin{tabular}{lrrr}
\hline Source & df & Mean square & $\boldsymbol{F}^{\mathbf{a}}$ \\
\hline Temperature (T) & 6 & $5,394.06$ & 1.207 \\
T-linear & 1 & 60.23 & 0.014 \\
T-quadratic & 1 & $22,882.00$ & $5.123 *$ \\
T-cubic & 1 & $5,206.26$ & 1.166 \\
Lack of fit & 3 & $1,405.18$ & 0.315 \\
Whole unit error & 13 & $4,466.84$ & \\
Leaf wetness (W) & 5 & $11,184.30$ & $39.471 * *$ \\
W-linear & 1 & $52,716.00$ & $186.041 * *$ \\
W-quadratic & 1 & $2,464.53$ & $8.698 *$ \\
Lack of fit & 3 & 247.01 & 0.872 \\
T $\times$ W & 30 & 609.53 & $2.151 *$ \\
T-linear $\times$ W-linear & 1 & 374.57 & 1.332 \\
T-linear $\times$ W-quad & 1 & 168.15 & 0.593 \\
T-quad $\times$ W-linear & 1 & $10,550.00$ & $37.232 * *$ \\
T-quad $\times$ W-quad & 1 & 512.23 & 1.808 \\
T-cub $\times$ W-linear & 1 & $1,553.59$ & $5.483 *$ \\
T-cub $\times$ W-quad & 1 & 841.18 & 2.969 \\
Lack of fit & 24 & 178.66 & 0.630 \\
Subunit error & 65 & 283.31 & \\
Flat-to-flat error & 240 & 103.50 & \\
\hline$*$ and $* *$. & & &
\end{tabular}

a $*$ and $* *=$ statistical significance at probability levels $P=0.05$, and $P=0.01$, respectively.

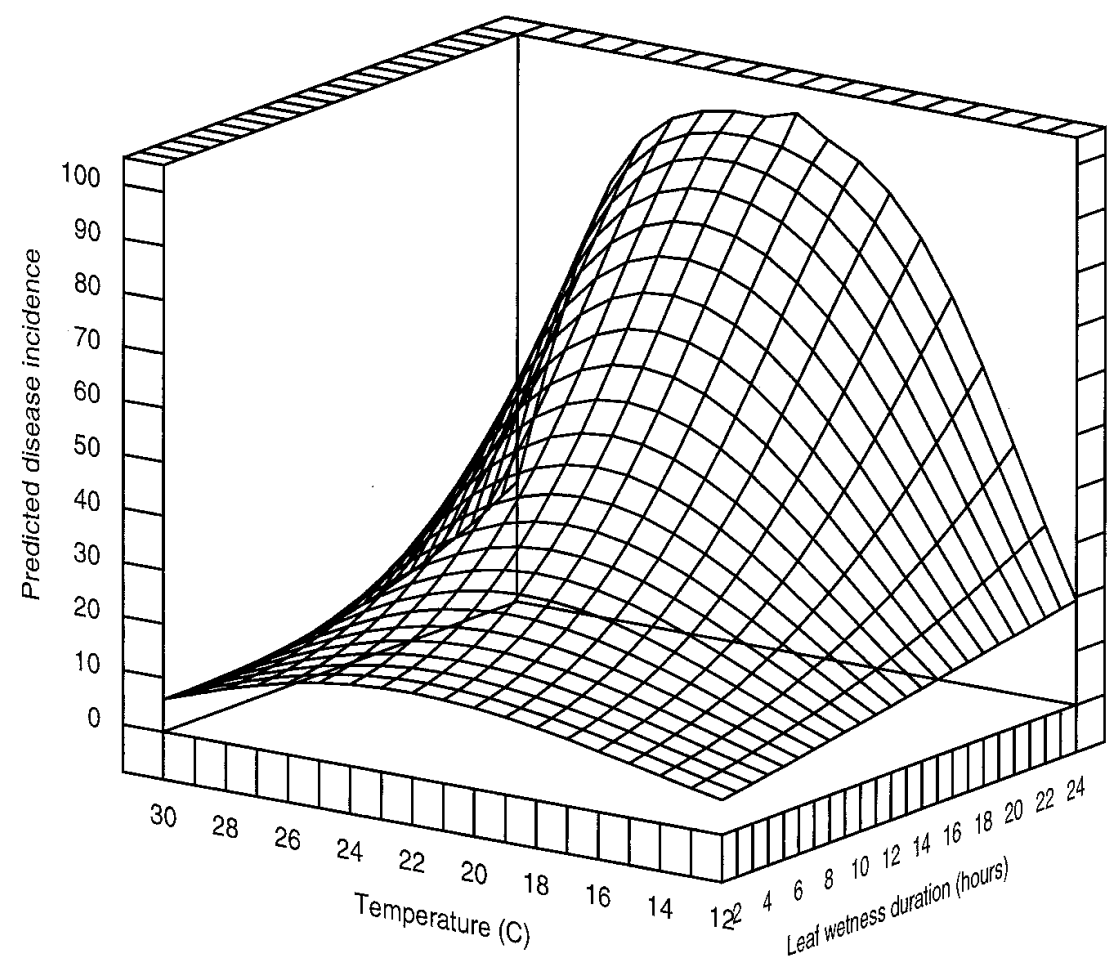

Fig. 2. A response surface based on the polynomial model (eq. 2) describing the influence of temperature and leaf wetness duration on infection of watermelon by Colletotrichum orbiculare. $b_{8} T^{3} W+E$, where $Y$ is disease incidence, $T$ is temperature, and $W$ is leaf wetness duration. The parameter estimates and their standard errors are listed in Table 2. The lack of significance of many of the parameter estimates is not surprising due to high correlations with other independent variables in the model. The response surface of the above model is shown in Figure 2. The unadjusted and adjusted coefficients of determination for the model in equation 2 were 0.90 and 0.87 , respectively. A random pattern of residuals occurred over a range of predicted means.

\section{DISCUSSION}

Based on our results, temperature and leaf wetness duration were clearly important factors in infection of watermelon by $C$. orbiculare. The largest contributors to the response surface were $T$-quadratic, $W$-linear, and the interaction between them. The significance of these terms explained the linear increase in incidence when plotted against leaf wetness duration (Fig. 1A) and the parabolic nature of disease incidence when plotted against temperature (Fig. 1B).

The optimum temperature range for infection determined by our research (21 to $24^{\circ} \mathrm{C}$ ) compares favorably with other reports on the influence of environment on anthracnose caused by $C$. orbiculare $(6,13,17)$. The optimum temperature range for anthracnose development on spiny cocklebur (X. spinosum) was 20 to $25^{\circ} \mathrm{C}$ (13). Thompson and Jenkins reported that anthracnose lesions on cucumber expanded rapidly at 20 to $28^{\circ} \mathrm{C}$ and conidia production was greatest at $24^{\circ} \mathrm{C}$ during the early stages of lesion development (17). Ishida and Akai (8) reported that conidia of $C$. orbiculare germinated readily within a range of 20 to $32^{\circ} \mathrm{C}$, and that appressoria formation was optimum at 20 to $26^{\circ} \mathrm{C}$. The lower and upper temperature limits for infection also appear to be described accurately by the model given in equation 2 . Littrell and Epps (12) observed no anthracnose infection on cucumber below $10^{\circ} \mathrm{C}$, and MacRae and Auld (13) showed only a minimum of disease development at $35^{\circ} \mathrm{C}$, despite a $24-\mathrm{h}$ dew period. That these temperature ranges for infection are

Table 2. Estimates of parameters from equation 2 for temperature and leaf wetness duration effects on infection of watermelon seedlings by Colletotrichum orbiculare

\begin{tabular}{lrr}
\hline Parameter & $\begin{array}{c}\text { Parameter } \\
\text { estimate }\end{array}$ & $\begin{array}{c}\text { Standard } \\
\text { error }\end{array}$ \\
\hline $\mathrm{b}_{0}$ & 59.8619 & 96.0062 \\
$\mathrm{~b}_{1}$ & -6.1378 & 14.9549 \\
$\mathrm{~b}_{2}$ & 0.3008 & 0.7403 \\
$\mathrm{~b}_{3}$ & -0.0048 & 0.0117 \\
$\mathrm{~b}_{4}$ & 4.3679 & 7.2389 \\
$\mathrm{~b}_{5}$ & 0.0547 & 0.0196 \\
$\mathrm{~b}_{6}$ & -1.2413 & 1.1251 \\
$\mathrm{~b}_{7}$ & 0.0899 & 0.0557 \\
$\mathrm{~b}_{8}$ & -0.0018 & 0.0009 \\
\hline
\end{tabular}


correctly identified is supported by observed anthracnose outbreaks in Indiana watermelon fields during midsummer, when evening temperatures are near or at their highest. Also, during a 3-week period of extremely rapid anthracnose increase on watermelon in experimental field plots in 1995 , temperatures during wet periods ranged from 20.2 to $25.1^{\circ} \mathrm{C}$, with a mean of $23.4^{\circ} \mathrm{C}$ (R. Latin, unpublished).

As expected, anthracnose incidence increased with the length of the period of leaf wetness. Our results are supported by other research on cucurbit anthracnose, where maximum disease development occurred with $\geq 16 \mathrm{~h}$ of leaf wetness $(13,17)$. This type of relationship between disease and moisture has been well documented for a variety of plant diseases (2).

The relatively high amount of disease that occurred at $12^{\circ} \mathrm{C}$, especially after only $2 \mathrm{~h}$ and $4 \mathrm{~h}$ of leaf wetness, warrants explanation. Evans et al. (5) observed similar results with Alternaria leaf blight of muskmelon. They attributed unexpectedly high levels of disease to infections enhanced by chilling injury suffered by plants after being transferred from a 25 to $27^{\circ} \mathrm{C}$ greenhouse environment to the $12^{\circ} \mathrm{C}$ growth chamber. Chandler and Thomas (3) had already demonstrated the role of mechanical injury in enhancing development of the disease. However, no such relationship has been reported for infection of watermelon seedlings by $C$. orbiculare. There also is no evidence to suggest that any of the disease processes characteristic of cucurbit anthracnose are favored at or near $12^{\circ} \mathrm{C}$. It is likely that prolonged drying times of the soilless potting medium, especially at lower temperatures, may be responsible. Drying time on foliage (determined visually) ranged from less than $5 \mathrm{~min}\left(30^{\circ} \mathrm{C}\right)$ to around $25 \min \left(12^{\circ} \mathrm{C}\right)$ but probably had little effect on resulting amounts of infection. However, the drying time of the soilless potting medium could have been as long as several hours or more. We suppose that at $12^{\circ} \mathrm{C}$, the substrate remained moist for a prolonged period, affording conidia accumulated at the base of the stem additional time to germinate and infect.

An empirical disease warning system has been developed by Duthie et al. (4), indicating that the relationship between anthracnose development and weather can be used to time fungicide sprays and achieve some degree of control (compared with unsprayed plots) with fewer applications than the weekly spray schedule. However, defoliation percentages in plots sprayed according to their weather-based program were four times greater than the defoliation percentages observed in plots sprayed weekly, suggesting the need for an improved model. Results of our research will be used in the development of a fundamental forecaster for anthracnose on watermelon. Decision rules for scheduling fungicide applications currently are being tested in the field. It is intended that this model for indexing environmental conditions in terms of favorability for anthracnose development will be incorporated into the Melcast system (10) already in use by Indiana melon growers.

\section{ACKNOWLEDGMENTS}

We thank W. E. Nyquist for assistance with data analysis.

\section{LITERATURE CITED}

1. Amin, K. S., and Ullasa, B. A. 1981. Effect of thiophanate on epidemic development of anthracnose and yield of watermelon. Phytopathology 71:20-22.

2. Campbell, C. L., and Madden, L. V. 1990. Introduction to Plant Disease Epidemiology. John Wiley \& Sons, New York.

3. Chandler, L. D., and Thomas, C. E. 1991. Effect of leaf miner feeding activity on the incidence of Alternaria leaf blight lesions on muskmelon leaves. Plant Dis. 75:938-940.

4. Duthie, J., Roberts, W., and Thannisch, T.
1995. Weather-based schedules for fungicidal control of watermelon anthracnose. (Abstr.) Phytopathology 85:510.

5. Evans, K. J., Nyquist, W. E., and Latin, R. X. 1992. A model based on temperature and leaf wetness duration for establishment of Alternaria leaf blight of muskmelon. Phytopathology 82:890-895.

6. Gardner, M. W. 1918. Anthracnose of cucurbits. U.S. Dep. Agric. Bull. 727.

7. Gardner, M. W., and Gilbert, W. W. 1921. Field tests with cucumber angular leaf-spot and anthracnose. Phytopathology 11:298-299.

8. Ishida, N., and Akai, S. 1969. Relation of temperature to germination of conidia and appressorium formation in Colletotrichum lagenarium. Mycologia 61:382-386.

9. Latin, R. X. 1993. Diseases and pests of muskmelons and watermelons. BP-44, Purdue University Cooperative Extension Service, West Lafayette, IN.

10. Latin, R., and Evans, K. J. 1996. Development and delivery of a forecaster for Alternaria leaf blight of muskmelon. (Abstr.) Phytopathology 86:S106.

11. Leben, C., and Daft, G. C. 1968. Cucumber anthracnose: Influence of nightly wetting of leaves on number of lesions. Phytopathology 58:264-265.

12. Littrell, R. H., and Epps, W. M. 1965. Standardization of a procedure for artificial inoculation of cucumbers with Colletotrichum lagenarium. Plant Dis. Rep. 49:649-653.

13. McRae, C. F., and Auld, B. A. 1988. The influence of environmental factors on anthracnose of Xanthium spinosum. Phytopathology 78:1182-1186.

14. Monroe, J. S. 1996. A model defining the relationship between temperature, leaf wetness duration, and infection by Colletotrichum orbiculare. M.S. thesis, Purdue University, West Lafayette, IN.

15. Peregrine, W. T. H., and Ahmad, K. B. 1983. Chemical and cultural control of anthracnose (Colletotrichum lagenarium) in watermelon. Trop. Pest Manage. 29:42-46.

16. Steel, R. G. D., and Torrie, J. H. 1980. Principles and Procedures of Statistics. McGraw Hill, New York.

17. Thompson, D. C., and Jenkins, S. F. 1985. Effect of temperature, moisture, and cucumber cultivar resistance on lesion size increase and conidial production by Colletotrichum lagenarium. Phytopathology 75:828-832. 